\title{
National trends in utilization and outcomes of coronary revascularization procedures among people with and without type 2 diabetes in Spain (2001-2011)
}

Ana Lopez-de-Andres ${ }^{1 *}$, Rodrigo Jimenez-García', Valentin Hernandez-Barrera', Napoleon Perez-Farinos², Jose M de Miguel-Yanes ${ }^{3}$, Manuel Mendez-Bailon ${ }^{4}$, Isabel Jimenez-Trujillo', Angel Gil de Miguel',

Carmen Gallardo Pino ${ }^{1}$ and Pilar Carrasco-Garrido ${ }^{1}$

\begin{abstract}
Background: Diabetes is associated with a high risk of death due to coronary artery disease (CAD). People with diabetes suffering from CAD are frequently treated with revascularization procedures. We aim to compare trends in the use and outcomes of coronary revascularization procedures in diabetic and non-diabetic patients in Spain between 2001 and 2011.

Methods: We identified all patients who had undergone coronary revascularization procedures, percutaneous coronary interventions $(\mathrm{PCl})$ and coronary artery bypass graft (CABG) surgeries, using national hospital discharge data. Discharges were grouped by diabetes status: type 2 diabetes and no diabetes. The incidence of discharges attributed to coronary revascularization procedures were calculated stratified by diabetes status. We calculated length of stay and in-hospital mortality (IHM). We apply joinpoint log-linear regression to identify the years in which changes in tendency occurred in the use of PCI and CABG in diabetic and non-diabetic patients. Multivariate analysis was adjusted by age, sex, year and comorbidity (Charlson comorbidity index).

Results: From 2001 to 2011, 434,108 PCls and 79,986 CABGs were performed. According to the results of the joinpoint analysis, we found that sex and age-adjusted use of PCl increased by 31.4\% per year from 2001 to 2003, by 15.9\% per year from 2003 to 2006 and by 3.8\% per year from 2006 to 2011 in patients with diabetes. IHM among patients with diabetes who underwent a PCl did not change significantly over the entire study period (OR 0.99; 95\% Cl 0.97-1.00).

Among patients with diabetes who underwent a CABG, the sex and age-adjusted CABG incidence rate increased by 10.4\% per year from 2001 to 2003, and then decreased by 1.1\% through 2011. Diabetic patients who underwent a CABG had a 0.67 (95\% Cl 0.63-0.71) times lower probability of dying during hospitalization than those without diabetes. Conclusions: The annual percent change in $\mathrm{PCl}$ procedures increased in diabetic and non-diabetic patients. Higher comorbidity and the female gender are associated with a higher IHM in $\mathrm{PCl}$ procedures. In diabetic and non-diabetic patients, we found a decrease in the use of CABG procedures. IHM was higher in patients without diabetes than in those with diabetes.
\end{abstract}

Keywords: Type 2 diabetes, Percutaneous coronary intervention, Coronary artery bypass graft surgery, Hospitalization, Length of stay, In-hospital mortality

\footnotetext{
* Correspondence: ana.lopez@urjc.es

${ }^{1}$ Preventive Medicine and Public Health Department, Health Sciences Faculty,

Rey Juan Carlos University, Madrid, Spain

Full list of author information is available at the end of the article
} 


\section{Background}

Diabetes is associated with a high risk of death due to coronary artery disease (CAD). Current figures indicate that cardiovascular events are responsible for $80 \%$ of all deaths in patients with diabetes [1]. In Spain, $75 \%$ of patients with diabetes die primarily of CAD [2]. Recent studies reported declines in cardiovascular mortality in patients with diabetes [3-6], which has been attributed to better management of risk factors; however, these have been less pronounced than in those without diabetes [7].

People with diabetes represent an increasing proportion of CAD patients, many of whom are treated with revascularization procedures [8]. Approximately $25 \%$ of all coronary revascularization procedures performed each year in the US are done on patients with diabetes [9]. Coronary revascularization for patients with diabetes can be achieved using coronary artery bypass graft (CABG) surgeries or percutaneous coronary interventions (PCIs) [10]. While PCI is more commonly used in patients affected by singlevessel $C A D$, the best strategy for patients with advanced $C A D$ is still debated, due to a higher repeat revascularization rate at 1-year follow-up in patients treated using PCI [11].

Kappetein AP et al. reported the 5-year results of the SYNTAX trial with regard to patients with diabetes. Of 1800 patients in the SYNTAX trial, 452 had diabetes. In this group of diabetic patients, 5-year rates for major adverse cardiac and cerebrovascular events (46 vs. $29 \%$; $\mathrm{P}<0.001$ ) and repeat revascularization (35 vs. $15 \%$; $\mathrm{P}<0.001$ ) were significantly higher for PCI vs. CABG [12].

The FREEDOM Trial Investigators found that, in patients with diabetes and advanced CAD, CABG was superior to PCI using first generation drug-eluting stents. The benefit of CABG stemmed from the differences in the rates of both AMI $(\mathrm{p}<0.001)$ and death from any cause $(p=0.049)$ [13].

Secular trends in the use of coronary revascularization procedures have been examined.

In the UK, Vamos et al. found that PCI rates increased significantly (IRR 1.01 [95\% CI 1.005-1.03]) in people with diabetes from 2004-2009, whereas CABG rates declined [14]. However, there are no studies investigating national trends in the use of coronary revascularization procedures in people with diabetes in Spain.

In this study, we used national hospital discharge data to describe and compare trends in the use of coronary revascularization procedures in diabetic and non-diabetic patients between 2001 and 2011 in Spain. In particular, we analyzed trends in the use of CABG and PCI, patient comorbidities, and in-hospital outcomes such as length of stay and in-hospital mortality.

\section{Methods}

A retrospective, descriptive, epidemiological study was conducted using the Spanish National Hospital Database (CMBD, Conjunto Minimo Básico de Datos), which compiles all public and private hospital data, hence covering more than $95 \%$ of hospital discharges [15]. The CMBD database is managed by the Spanish Ministry of Health, Social Services and Equality and includes patient variables (sex, date of birth), date of admittance, date of discharge, up to 14 discharge diagnoses, and up to 20 procedures performed during hospitalization. The Spanish Ministry of Health, Social Services and Equality sets recording standards and performs periodic audits [15].

We selected all surgical admissions of patients who underwent coronary revascularization procedures using the International Classification of Diseases - Ninth Revision, Clinical Modification (ICD-9-CM). The procedure codes used were: 36.10-36.19 for CABG and 36.06; 36.07; 36.09; 00.66 for PCI.

Discharges were grouped by diabetes status as follows: no diabetes and type 2 diabetes (ICD-9-CM codes: 250. $\mathrm{x} 0 ; 250 . x 2)$. Patients with type 1 diabetes were excluded (ICD-9-MC codes: 250.x1; 250.x3).

Patients who underwent both CABG and PCI during their hospitalization were excluded.

The outcomes of interest included the percentage of patients who died during hospitalization, defined as inhospital mortality (IHM) and the mean length of hospital stay (LOS).

Clinical characteristics included information on overall comorbidity at the time of surgery, which was assessed by computing the Charlson comorbidity index (CCI). The index applies to 17 disease categories whose scores are totaled to obtain an overall score for each patient [16]. The index is subsequently categorized into three levels: 0 , no disease; 1 , one or two diseases; and 2, three or more diseases [17]. To calculate the CCI, we used 17 disease categories, excluding diabetes and AMI, as described by Thomsen RW et al. [17].

\section{Statistical analysis}

A descriptive statistical analysis was performed. Rates for type 2 diabetic and non-diabetic patients for each coronary revascularization procedure were calculated in terms of 100,000 inhabitants. We also calculated the yearly age- and sex-specific incidence rates for diabetic and non-diabetic patients, dividing the number of cases per year, sex, and age group by the corresponding number of people in that population group, according to data from the Spanish National Institute of Statistics, as reported on December 31 of each year [18].

In our study, we used joinpoint log-linear regression to identify the years in which changes in tendency occurred in the use of PCI and CABG in patients with and 
without type 2 diabetes, as well as to estimate the annual percentage of change (APC) in each of the periods delimited by the points of change. The analysis started with the minimum number of joinpoints and tested whether the inclusion of one or more joinpoints was statistically significant [19]. In the final model, each joinpoint indicated a significant change in the tendency, and the APC was obtained in each of the segments delimited by the joinpoints, using the weighted least squares technique. The Joinpoint Regression Program Version 4.0.4 was used for the analysis [20].

In order to test the time trend for IHM, logistic regression analyses were performed with mortality as a binary outcome, using year of discharge, sex, age, and CCI as independent variables. Models were generated for diabetic and non-diabetic subjects and for the entire population, in order to compare the IHM of those who have the disease and those who do not. Statistical analyses were performed using Stata version 10.1 (Stata, College Station, Texas, USA). Statistical significance was set at $\mathrm{p}<0.05$ (2-tailed).

\section{Ethical aspects}

Data confidentiality was maintained at all times according to Spanish legislation. Patient identifiers were deleted before the database was provided to the authors, in order to maintain patient anonymity. It is not possible to identify patients at individual levels, either in this article or in the database. Given the anonymous and mandatory nature of the dataset, it was not necessary to obtain informed consent. The study protocol was approved by the ethics committee of the Universidad Rey Juan Carlos.

\section{Results}

From 2001 to 2011, a total of 514,094 admissions of patients who underwent scheduled or unscheduled coronary revascularization procedures were recorded in Spain. Over the study period, $29.8 \%(\mathrm{n}=153,242)$ of all patients who underwent coronary revascularization procedures had type 2 diabetes. There were 434,108 PCIs $(29.2 \%$ [ $n=126,776$ ] in patients with type 2 diabetes) and 79,986 CABGs (33.0\% $[n=26,466]$ in patients with type 2 diabetes).

\section{Percutaneous coronary intervention}

In patients who underwent a PCI, there was a significant male predominance in patients both with and without diabetes (69.5\% and 79.9\%). Mean age was 67.5 years (SD, 10.1 years) in patients with type 2 diabetes and 63.9 years (SD, 12.1 years) in those without diabetes $(\mathrm{p}<0.01)$.

Patients with type 2 diabetes who underwent PCIs had higher CCI values compared to those without diabetes (37.2\% vs. $27.1 \%$ with one or more coexisting conditions, respectively).
Among those who received a PCI, the median LOS was significantly higher in patients with type 2 diabetes (6.0 days [IQR 11.0 days]) compared to those without diabetes (5.0 days [IQR 7.0 days]). Also, IHM was significantly higher in patients with type 2 diabetes (2.5\%) compared to patients without diabetes (2.0\%).

According to the results of the joinpoint analysis, we found that sex and age-adjusted use of PCI increased by $31.4 \%$ per year from 2001 to 2003 , by $15.9 \%$ per year from 2003 to 2006 and by $3.8 \%$ per year from 2006 to 2011 in patients with type 2 diabetes (Figure 1). In patients without diabetes, the use of PCI increased by $12.1 \%$ per year from 2001 to 2005 and by $3.6 \%$ per year from 2005 to 2009. From 2009 to 2011, it decreased by $1.39 \%$ per year, but not significantly (Figure 2 ).

Table 1 shows time trend outcomes in annual PCIs in patients with and without type 2 diabetes in Spain, 2001-2011. We found that the mean age of patients with diabetes who underwent a PCI was $66.1 \pm 9.7$ years in 2001 and increased to $68.2 \pm 10.4$ years in $2011(\mathrm{P}<0.05)$, the proportion of men varied significantly from $67.1 \%$ in 2001 to $71.3 \%$ in 2011 and the prevalence of those with a $\mathrm{CCI}$ of one or more increased from $30.5 \%$ in 2001 to 41.1 $(\mathrm{P}<0.05)$.

LOS after PCI decreased significantly over the study period in both groups of patients $(\mathrm{P}<0.01)$, showing higher values among those with type 2 diabetes in all years analyzed (Table 1).

The IHM among those who underwent a PCI increased for those without diabetes $(1.9 \%$ in 2001 vs. $2.3 \%$ in 2011; $\mathrm{P}<0.05)$ but remained stable for those suffering from type 2 diabetes $(1.9 \%$ vs. $2.5 \%, \mathrm{P}=0.10)$ (Table 1$)$.

As can been seen in Table 2, after multivariate adjustment, the IHM among patients with diabetes who underwent a PCI did not change significantly from 2001 to 2011 (OR 0.99; 95\% CI 0.97-1.00). IHM was significantly higher in women than in men (OR 1.36; 95\% CI 1.26-1.46) and was higher in those with one or two (OR 2.92; 95\% CI 2.71-3.15) or three or more (OR 5.27; 95\% CI 4.51-6.15) comorbidities associated with type 2 diabetes.

\section{Coronary artery bypass graft}

We found that, in patients who underwent a CABG, the mean age was significantly higher in patients with type 2 diabetes than in those without diabetes (67.3 years [SD 8.7 years] vs. 66.4 years [SD 10.1 years]) and there was higher proportion of males undergoing CABG procedures in both groups $(73.3 \%$ in patients with type 2 diabetes vs. $80.3 \%$ in patients without diabetes, $\mathrm{P}<0.05$ ).

In our study, patients with diabetes who underwent a CABG had higher CCI values than those without diabetes ( $40.8 \%$ vs. $36.3 \%$ with one or more comorbidities).

In patients with type 2 diabetes, the IHM was significantly lower than in those without diabetes $(5.8 \%$ vs. 


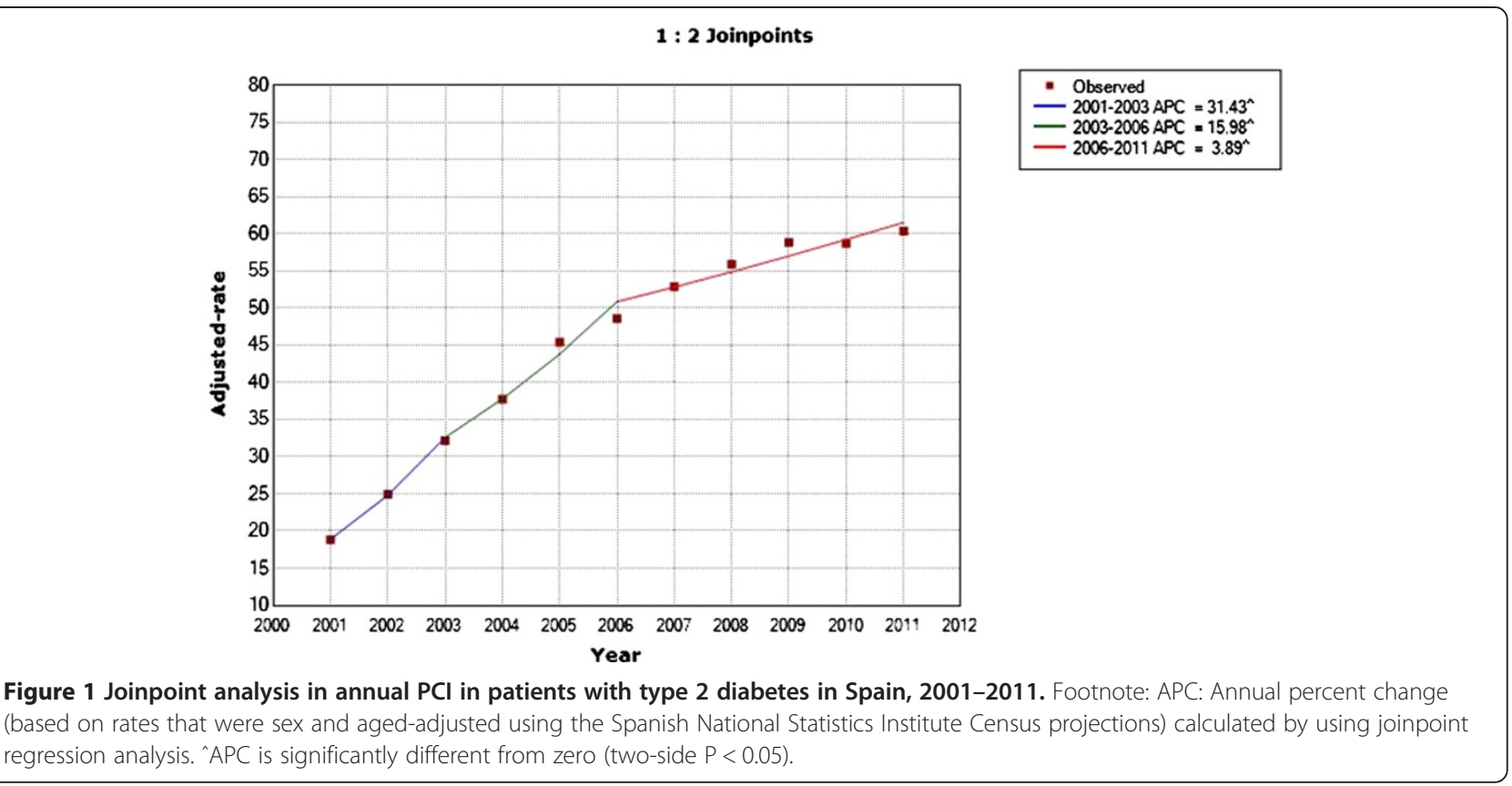

7.9\%); however the median LOS was significantly higher in patients with type 2 diabetes (16 days [IQR 16 days] compared with those without diabetes (15 days [IQR 15 days]).

Among patients with type 2 diabetes who underwent CABG, the sex and age-adjusted CABG incidence rate increased by $10.4 \%$ per year from 2001 to 2003, then decreased by $1.1 \%$ through 2011 (Figure 3). In patients without diabetes, the incidence rate decreased at a constant rate of $3.94 \%$ per year over the entire period of study (Figure 4).
As can be seen in Table 3, over the 11-year study period, the mean age of patients with type 2 diabetes who underwent CABG was $66.1 \pm 8.6$ years in 2001 and $67.8 \pm 8.7$ years in 2011. Significant differences in age were observed $(\mathrm{P}<0.01)$. In 2001 the proportion of men was $70.8 \%$, which rose to $76.4 \%$ in 2011 $(\mathrm{P}<0.05)$.

In our study, LOS in patients with type 2 diabetes decreased significantly from 18 days (IQR, 17 days) in 2001 to 14 days (IQR, 14 days) in 2011. In patients
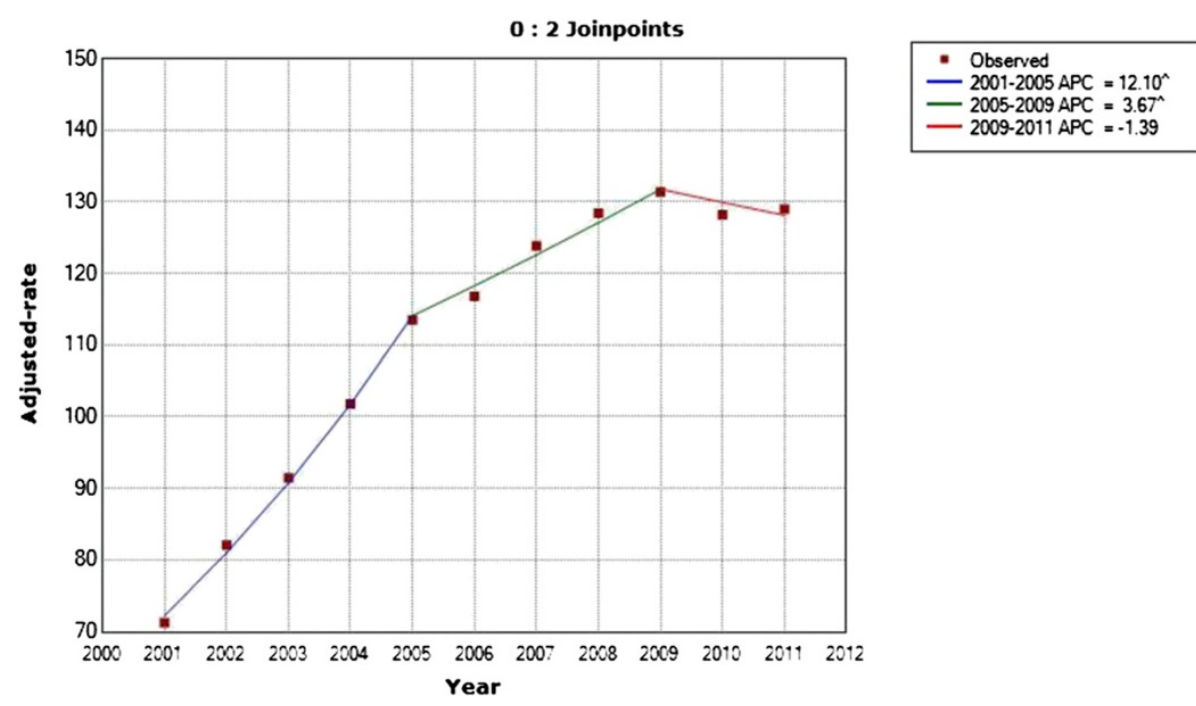

Figure 2 Joinpoint analysis in annual PCI in patients without type 2 diabetes in Spain, 2001-2011. Footnote: APC: Annual percent change (based on rates that were sex and aged-adjusted using the Spanish National Statistics Institute Census projections) calculated by using joinpoint regression analysis. ^APC is significantly different from zero (two-side $P<0.05$ ). 
Table 1 Characteristics and outcomes of hospital discharges after percutaneous coronary intervention among patients with and without type 2 diabetes in Spain, 2001-2011

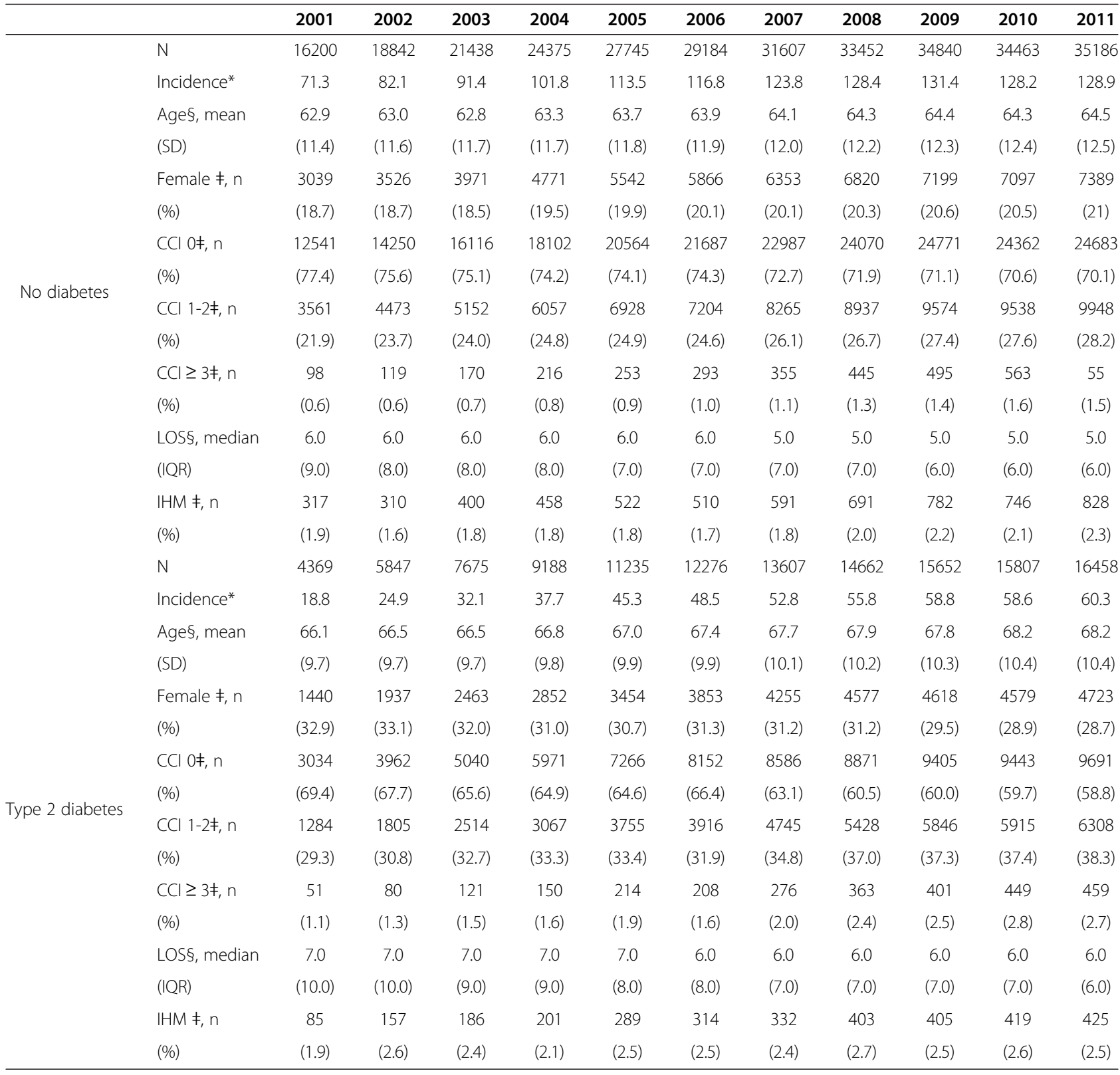

$\mathrm{N}$ : Number of procedures; LOS: length of stay; IHM: In-hospital mortality;

$\mathrm{CCl}$ (Charlson Comorbidity Index): Comorbidities included in the Charlson comorbidity index, except diabetes and AMI.

Incidence per 100.000. Incidence was calculated using the Spanish National Statistics Institute census projections adjusted by sex and age (16).

${ }^{*} \mathrm{P}<0.05$ (Poisson regression analysis).

$\S \mathrm{P}<0.05$ (ANOVA or Kruskal-Wallis analysis)

$\neq P<0.05$ ( $X 2$ linear tend analysis).

without diabetes, LOS also decreased significantly over the period of study (Table 3).

The IHM decreased significantly for those with and without diabetes during the 11-year study period $(7.1 \%$ in 2001 vs. $4.4 \%$ in 2011 and $9.5 \%$ vs. $6.7 \%$, respectively) (Table 3).

After multivariate adjustment, the IHM among patients with type 2 diabetes who underwent a CABG decreased significantly over the entire study period (OR 0.93; 95\% CI 0.91-0.94), was significantly higher in women than in men (OR 1.69; 95\% CI 1.52-1.89) and in those with one or two (OR 2.58; 95\% CI 2.31-2.88) and with three or more (OR 4.95; 95\% CI 3.83-6.42) comorbidities. Patients suffering from type 2 diabetes who underwent a CABG had a 0.67 (95\% CI 0.63-0.71) times lower probability of dying during hospitalization than those without diabetes (Table 2). 
Table 2 Multivariate analysis of the factors associated with in-hospital mortality after coronary revascularization procedures among patients with and without type 2 diabetes in Spain, 2001-2011

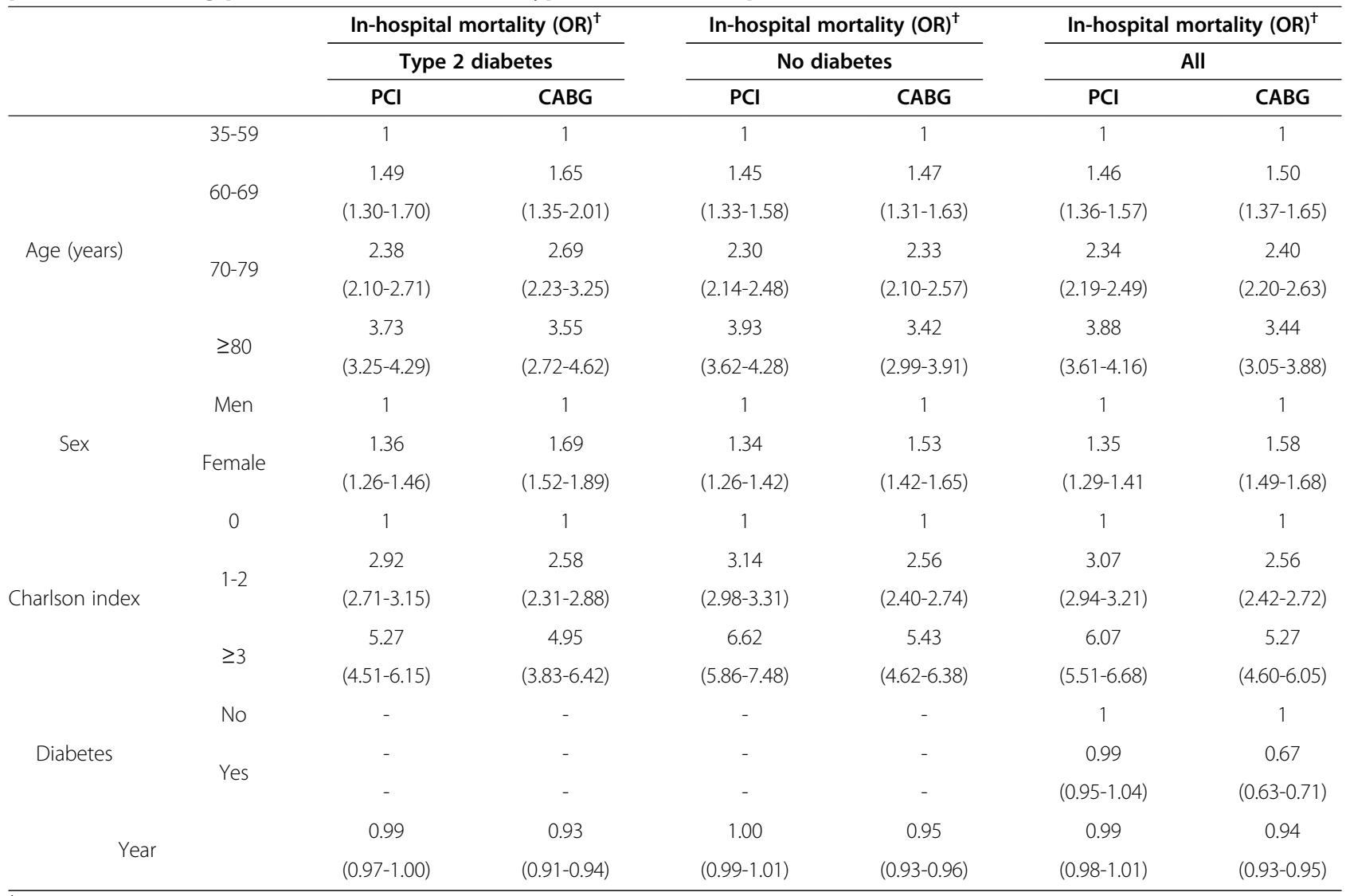

${ }^{+}$Calculate using logistic regression models: Odds Ratio (OR). The logistic regression multivariate model were built using as dependent variable"death (yes/no)" of $\mathrm{PCl}$ or CABG respectively, and as independent variables year, sex, Charlson comorbidity index and age.

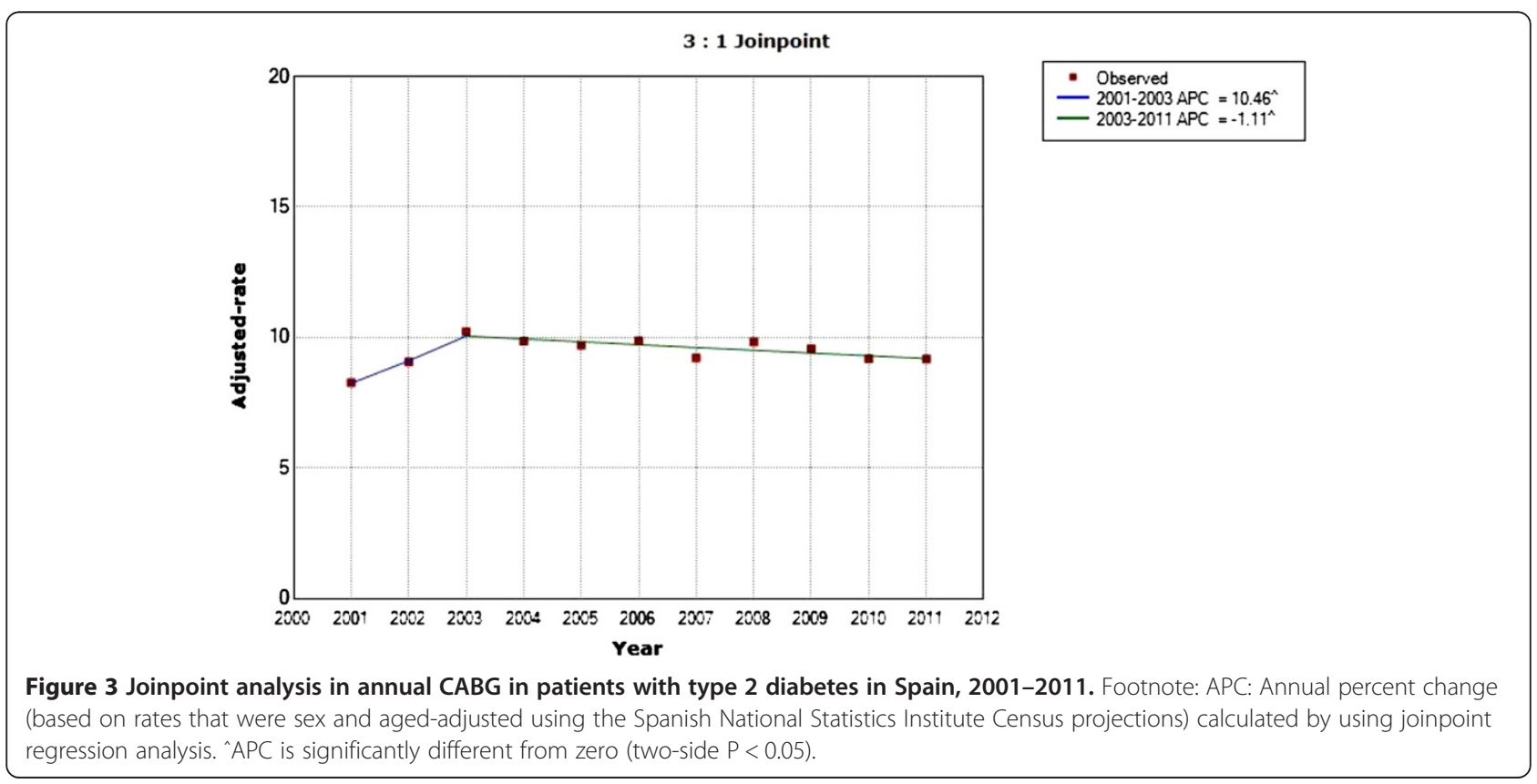




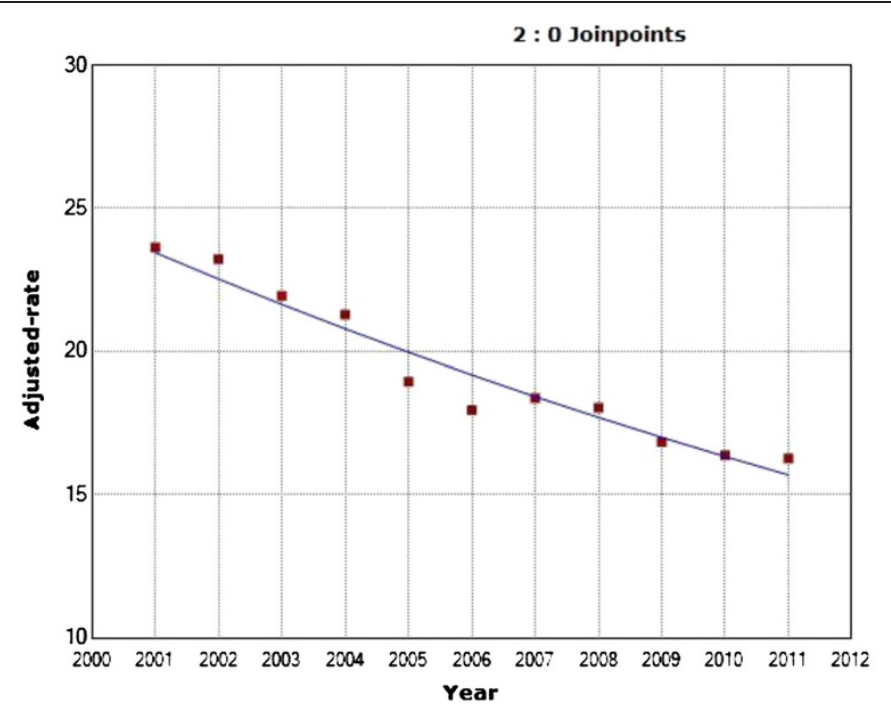

- Observed $2001-2011 \mathrm{APC}=-3.94^{\wedge}$

Figure 4 Joinpoint analysis in annual CABG in patients without type 2 diabetes in Spain, 2001-2011. Footnote: APC: Annual percent change (based on rates that were sex and aged-adjusted using the Spanish National Statistics Institute Census projections) calculated by using joinpoint regression analysis. ^APC is significantly different from zero (two-side $P<0.05$ ).

\section{Discussion}

Using the Spanish National Hospital Database, we found different trends over the last 11 years in the hospitalizations of subjects with and without type 2 diabetes who underwent coronary revascularization procedures.

Our results reveal that patients with type 2 diabetes account for $29.8 \%$ of all revascularization procedures in Spain. We found an increase in PCI procedure rates from 2001 to 2011; and a decline in hospital admissions for CABG in patients with type 2 diabetes from 2003 to 2011.

Our national results are consistent with other studies indicating that PCI rates have increased significantly due to advances in stent device technology and adjunctive pharmacology and CABG rates have declined due to the fact that this procedure is more invasive than $\mathrm{PCI}$ procedures $[14,21,22]$. Rana et al. indicated that drug-eluting stents were used more often in patients with severe comorbidities and multivessel disease [23], but a recent study indicated that CABG in patients with diabetes and coronary artery disease offers advantages in terms of survival [24]. Another advantage of CABG procedures is with regard to the need for repeat revascularization. Contini et al. concluded that only $51.3 \%$ of PCI diabetic patients underwent "complete" revascularization, while 85.6\% of CABG patients with type 2 diabetes did so [25].

We found that IHM increased over time among nondiabetic patients after PCI. Vamos et al. observed that, among those without diabetes from 2004-5 to 2009-10, the percentage of patients who underwent a PCI and died in the hospital increased from $0.9 \%$ to $1.5 \%(\mathrm{p}<0.001)$. These authors suggest that this increase, despite technological advances in interventional techniques and improvements in periprocedural care, may be attributable to the increasing complexity of cases referred for PCI [14]. We agree with this interpretation, since in our population the CCI was significantly worse in 2001 than in 2011 (CCI $\geq 1 ; 22.5 \%$ and $29.7 \%$ respectively). Another possible explanation is that over the study period, in the group of patients without diabetes, there may have been an increase in the prevalence of subjects with undiagnosed glucose abnormalities, and consequently,with a higher risk of adverse cardiac effects [26,27]. Kassain et al., 2012 concluded that the risk of major adverse cardiovascular events following a PCI in diabetics with good glycemic control (HBA1c $\leq 7 \%)$ was not significantly different from that of non-diabetics (adjusted $\mathrm{HR}=1.33 ; 95 \%$ CI:0.38 to $4.68, \mathrm{P}=0.66)$ [28].

In our study, the IHM remained stable over time among diabetic patients with a PCI. The higher comorbidity and older age can partially explain this lack of improvement.

Holper et al. found significant improvements in mortality rates over time (9.7\% in 1997-1998; $6.5 \%$ in 1999 ; $4.1 \%$ in $2001-2002$; $5.4 \%$ in 2004 and $4.7 \%$ in 2006) in patients with diabetes treated with oral agents after a PCI [29].

On the other hand, Vamos et al. found significant increases in IHM rates for PCI from 2004 to 2010 [14].

A recent study in United States concluded that the mortality at 3-year follow-up after PCI, of patients with diabetes treated with oral agents, had significantly higher adjusted hazards of death (HR: 1.32 [95\% CI: 1.29 to1.35] compared to nondiabetic patients. The authors indicated that the mechanisms for this incremental risk 
Table 3 Characteristics and outcomes of hospital discharges after coronary artery bypass graft among patients with and without type 2 diabetes in Spain, 2001-2011

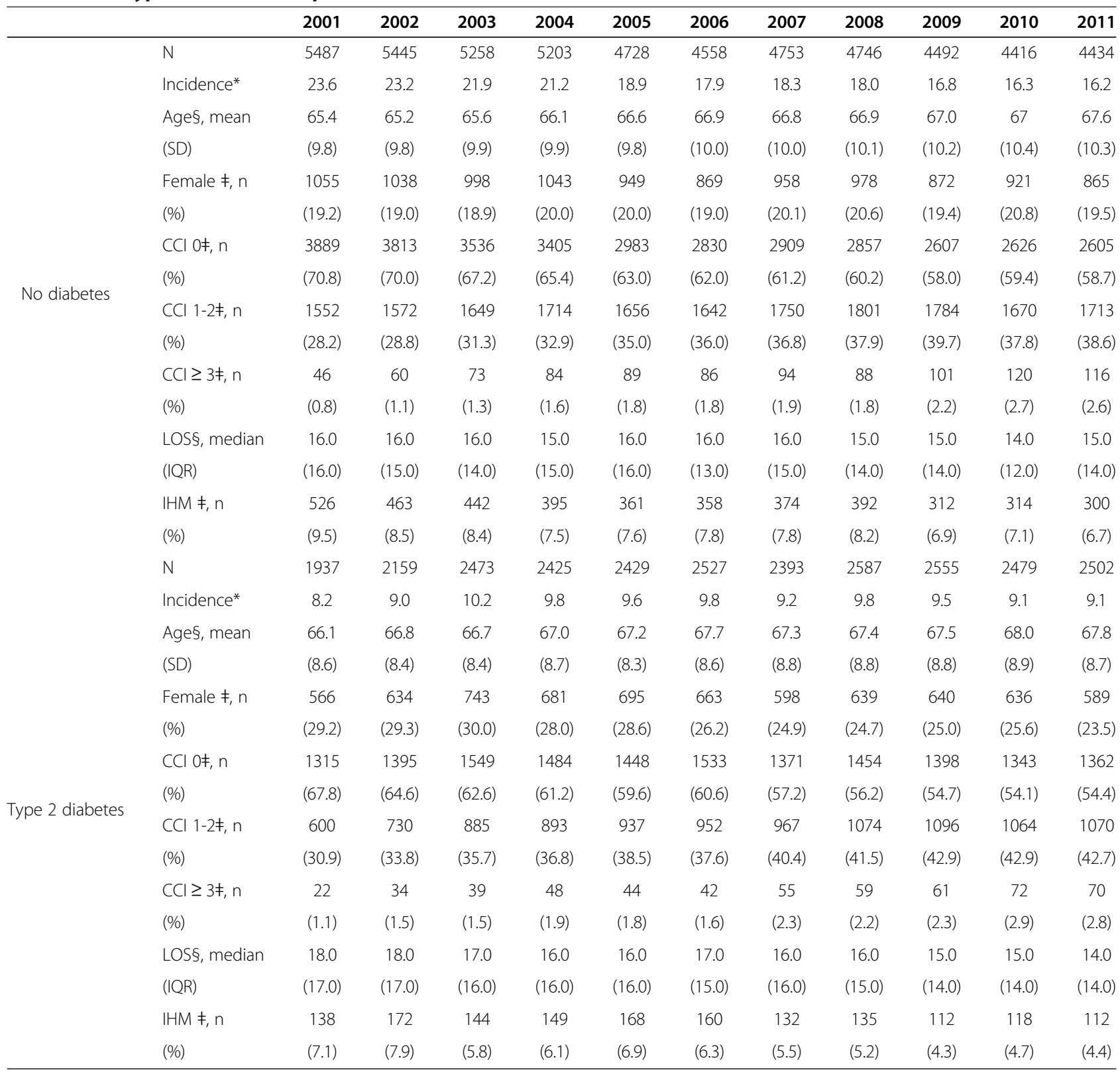

$\mathrm{N}$ : Number of procedures; LOS: length of stay; IHM: In-hospital mortality; CCI (Charlson Comorbidity Index): Comorbidities included in the Charlson comorbidity index, except diabetes and AMI.

Incidence per 100.000. Incidence was calculated using the Spanish National Statistics Institute census projections adjusted by sex and age (16).

${ }^{*} \mathrm{P}<0.05$ (Poisson regression analysis).

$\S \mathrm{P}<0.05$ (ANOVA or Kruskal-Wallis analysis).

$\mp P<0.05$ ( $X 2$ linear tend analysis).

are likely multifactorial: a greater underlying burden of atherosclerosis, microvascular disease, a prothrombotic state, more neointimal hyperplasia, greater vascular inflammation, and/or further accumulation of diabetesrelated end-organ damage and comorbidities during the follow-up period [30].

Incomplete revascularization is frequently the final outcome in patients with multivessel coronary disease who undergo PCI [25]. However, we found a significant decline in IHM in CABG patients. Hassan et al. (2010) explain that the greater improvement in CABG in-hospital mortality outcome versus PCI may be attributable to advanced myocardial protection techniques, superior perioperative critical care, and improved patient selection and surgical timing than in PCI patients [31]. 
Among those who underwent a CABG, we found that IHM was higher in patients without diabetes than in those with type 2 diabetes. In England, the IHM found in years 2009-10 among non-diabetic patients who underwent a CABG was $3.1 \%$ compared to $2.8 \%$ among diabetic patients [14]. However the reasons for these differences require further investigations with clinical data and longer follow-up outside the hospital.

In Canada, Elbarouni B et al. found that diabetic patients continue to experience worse outcomes, including IHM, when compared to those without diabetes. Paradoxically, these diabetic patients are treated with less invasive treatments compared to their nondiabetic counterparts [32]. Also in the same country, Kang et al. found that, among subjects who had antianginal use prior to non-ST-elevation acute coronary syndrome, the prevalence of diabetes was $36.5 \%$ and only $20.7 \%$ among those not using these medications. Furthermore, patients on chronic antianginal therapy before admission had lower rates of catheterization during hospitalization. This latter observation may be related to the fact that this group had significantly more comorbidities, as well as a higher burden of coronary disease at baseline than had been previously delineated, and might not be suited to revascularization [33].

In our investigation, the median LOS for PCI decreased from 7 days in 2001 to 6 days in 2011, among diabetic patients, and from 6 to 5 days among nondiabetics. With regard to CABG, the median was 18 days in 2001 and 14 days in 2011 for those suffering from diabetes, with equivalent figures of 16 and 15 days for those without the disease. It is remarkable that these figures are almost twice those reported by Vamos et al., in England, who found a median of 2 days for PCI and 9 days for CABG among those with and without diabetes in the 2009-10 period [14].

In Spain and in England, the medical insurance systems are very similar in terms of universal coverage, being funded by taxes and predominantly operating within the public sector [34,35]. Thus, we think these large differences may be explained by several reasons. First, the differences in the percentage of scheduled/emergency procedures between the two countries; with a much higher percentage of scheduled procedures in England. Second, the LOS in our investigation was calculated from the time the patient was admitted to the hospital and not from the time that the procedure was performed. We do not know whether the data for England was analyzed in the same way or whether they calculated only from the moment the procedure was performed until the patient was discharged. Finally, the severity of the CAD or the comorbidities was different between the two countries.
In line with the results discussed for LOS, we also find that IHM after CABG in Spain was higher than in England. With figures of $4.7 \%$ and $7.1 \%$ among diabetic and non-diabetic patients in the year 2010 in Spain, and corresponding figures for England of $2.8 \%$ and $3.1 \%$ in the 2009-10 period. These differences cannot be explained by patient characteristics, which are similar with regard to age and sex. Beside the aforementioned, another possible explanation for the improvement in England is that the prevention and treatment of cardiovascular disease and its risk factors have assumed increasing importance in UK health policy over the last decade; investments have been made in health services; the introduction of a wide range of initiatives; national treatment standards for the management of major chronic conditions with a special focus on secondary prevention $[14,22]$.

In type 2 diabetes patients who had undergone either a PCI or a CABG, women had worse outcomes than men. Our results are consistent with those of previous studies, which suggest that the worse effect of diabetes on outcomes in women might be related to the onset mechanism for cardiovascular disease, the success of the revascularization coronary procedure, and the higher burden of cardiovascular risk factors [21,36-38]. However, the worse results from these procedures among women call for urgent investigations to identify and reduce these significant differences.

The strength of our investigation lies in its large sample size, its 11-year follow-up period and its standardized methodology, which has previously been used to investigate diabetes and its complications in Spain and elsewhere $[39,40]$. Nevertheless, our study is subject to a series of limitations. Our data source was the CMBD, an administrative database that contains discharge data for Spanish hospitalizations and uses information the physician has included in the discharge report; therefore, it does not include all the variables of the clinical history such as the severity of the coronary disease or other chronic conditions, the duration of diabetes complications or treatment. Another limitation of this database is its anonymity (no identifying items such as clinical history number), which makes it impossible to detect whether the same patient was admitted more than once during the same year. In addition, patients who moved from one hospital to another would appear twice.

Nevertheless, this dataset, which was introduced in Spain in 1982, is a mandatory register, and its coverage is estimated to be greater than $95 \%$ [15]. We were unable to calculate diabetes-specific incidence rates, because no studies in Spain cover blood glucose measurements or HbA1C for the entire population; consequently, no precise estimate of the prevalence of diabetes is available [41]. Concerns have been raised about the accuracy of routinely-collected datasets; however, these datasets are 
periodically audited. Consequently, the quality and validity of our dataset has been assessed and shown to be useful for health research [42].

Another limitation of our study is the missing causal relationship between IHM and CAGD/PCI as cancer and non-cardiovascular admitted patients were also included, the mortality of whom may not have been affected by the CABG/PCI.

\section{Conclusions}

Our results show that the annual percentage change in PCI procedures increased in diabetic and non-diabetic patients. Outcomes such as LOS is worse among individuals with diabetes than those without diabetes for PCI although they improved over the entire study period for both groups. Higher comorbidity and female gender are associated with higher IHM in PCI procedures.

We found a decrease in the use of CABG procedures in patients with and without type 2 diabetes. IHM was higher in patients without type 2 diabetes than those with it.

Given the rapid increase in the prevalence of diabetes and the aging population, these findings emphasize the need for further improvement in the control of cardiovascular risk factors in people with diabetes.

\section{Abbreviations}

AMl: Acute myocardial infarction; APC: Annual percentage of change; CABG: Coronary artery bypass graft surgery; CAD: Coronary artery disease; CCl: Charlson comorbidity index; CMBD: Spanish Minimum Basic Data Set (Conjunto Mínimo Básico de Datos); ICD-9-CM: International Classification Diseases-Ninth Revision, Clinical Modification; IHM: In-hospital mortality; LOS: Length of stay; PCI: Percutaneous coronary intervention.

\section{Competing interests}

The authors declare that they have no competing interests.

\section{Authors' contributions}

AL and PCG researched data, contributed to the discussion, wrote the manuscript, and reviewed/edited the manuscript. RJG contributed to the discussion, wrote the manuscript, and reviewed/edited the manuscript. VHB researched data and reviewed/edited the manuscript. NPF, JMMY, MMB, IJT, AGM and CGP contributed to the discussion and reviewed/edited the manuscript. All authors reviewed and gave their final approval of the version to be submitted.

\section{Acknowledgements}

This study forms part of research funded by the FIS (Fondo de Investigaciones Sanitarias - Health Research Fund, grant no. PI13/00118, Instituto de Salud Carlos III).

\footnotetext{
Author details

${ }^{1}$ Preventive Medicine and Public Health Department, Health Sciences Faculty, Rey Juan Carlos University, Madrid, Spain. ${ }^{2}$ Agencia Española de Seguridad Alimentaria y Nutrición, Ministerio de Sanidad, Servicios Sociales e Igualdad, Madrid, Spain. ${ }^{3}$ Servicio de Medicina Interna, Hospital Universitario del Sureste, Madrid, Spain. ${ }^{4}$ Servicio de Medicina Interna, Hospital Clínico San Carlos, Madrid, Spain.
}

Received: 12 November 2013 Accepted: 18 December 2013 Published: 3 January 2014

\section{References}

1. Nelson SE: Management of patients with type 2 diabetes. Endocrinol Nutr 2002, 49:113-126.

2. Andrés $E$, Cordero A, Magán P, Alegría E, León M, Luengo E, Botaya RM, García Ortiz L, Casasnovas JA: Long-term mortality and hospital readmission after acute myocardial infarction: an eight-year follow-up study. Rev Esp Cardiol 2012, 65:414-420.

3. Booth GL, Kapral MK, Fung K, Tu JV: Recent trends in cardiovascular complications among men and women with and without diabetes. Diabetes Care 2006, 29:32-37.

4. Kamalesh M, Subramanian U, Ariana A, Sawada S, Tierney W: Similar decline in post-myocardial infarction mortality among subjects with and without diabetes. Am J Med Sci 2005, 329:228-233.

5. Norhammar A, Lindback J, Ryden L, Wallentin L, Stenestrand U: Improved but still high short- and long-term mortality rates after myocardial infarction in patients with diabetes mellitus: A time-trend report from the Swedish Register of Information and Knowledge about Swedish Heart Intensive Care Admission. Heart 2007, 93:1577-1583.

6. Svensson AM, Dellborg M, Abrahamsson P, Karlsson T, Herlitz J, Duval SJ, Berger AK, Luepker RV: The influence of a history of diabetes on treatment and outcome in acute myocardial infarction, during two time periods and in two different countries. Int J Cardio/ 2007, 119:319-325.

7. Thomas RJ, Palumbo PJ, Melton LJ, Roger VL, Ransom J, O'Brien PC, Leibson CL: Trends in the mortality burden associated with diabetes mellitus: A population-based study in Rochester, Minn, 1970-1994. Arch Intern Med 2003, 163:445-451.

8. Ryden L, Standl E, Bartnik M, Van den Berghe G, Betteridge J, de Boer MJ, Cosentino F, Jonsson B, Laakso M, Malmberg K, Priori S, Ostergren J, Tuomilehto J, Thrainsdottir I, Vanhorebeek I, Stramba-Badiale M, Lindgren P, Qiao Q, Priori SG, Blanc JJ, Budaj A, Camm J, Dean V, Deckers J, Dickstein K, Lekakis J, McGregor K, Metra M, Morais J, Osterspey A, et al: Guidelines on diabetes, pre-diabetes, and cardiovascular diseases: executive summary The Task Force on Diabetes and Cardiovascular Diseases of the European Society of Cardiology (ESC) and of the European Association for the Study of Diabetes (EASD). Eur Heart J 2007, 28:88-136.

9. Flaherty JD, Davidson CJ: Diabetes and coronary revascularization. JAMA 2005, 293:1501-1508.

10. Task Force on Myocardial Revascularization of the European Society of Cardiology (ESC) and the European Association for Cardio-Thoracic Surgery (EACTS); European Association for Percutaneous Cardiovascular Interventions (EAPCI), Wijns W, Kolh P, Danchin N, Di Mario C, Falk V, Folliguet T, Garg S, Huber K, James S, Knuuti J, Lopez-Sendon J, Marco J, Menicanti L, Ostojic M, Piepoli MF, Pirlet C, Pomar JL, Reifart N, Ribichini FL, Schalij MJ, Sergeant P, Serruys PW, Silber S, Sousa Uva M, Taggart D: Guidelines on myocardial revascularization. Eur Heart J 2010, 31:2501-2555.

11. Mercado N, Wjins W, Serruys PW, Sigwart U, Flather MD, Stables RH, O'Neill WW, Rodriguez A, Lemos PA, Hueb WA, Gersh BJ, Booth J, Boersma E: One-year outcomes of coronary artery bypass graft surgery versus percutaneous coronary intervention with multiple stenting for multisystem disease: a meta-analysis of individual patient data from randomized clinical trials. J Thorac Cardiovasc Surg 2005, 130:512-519.

12. Kappetein AP, Head SJ, Morice MC, Banning AP, Serruys PW, Mohr FW, Dawkins KD, Mack MJ, SYNTAX Investigators: Treatment of complex coronary artery disease in patients with diabetes: 5-year results comparing outcomes of bypass surgery and percutaneous coronary intervention in the SYNTAX trial. Eur J Cardiothorac Surg 2013, 43:1006-1013.

13. Farkouh ME, Domanski M, Sleeper LA, Siami FS, Dangas G, Mack M, Yang M, Cohen DJ, Rosenberg Y, Solomon SD, Desai AS, Gersh BJ, Magnuson EA, Lansky A, Boineau R, Weinberger J, Ramanathan K, Sousa JE, Rankin J, Bhargava B, Buse J, Hueb W, Smith CR, Muratov V, Bansilal S, King S 3rd, Bertrand M, Fuster V, FREEDOM Trial Investigators: Strategies for multivessel revascularization in patients with diabetes. $N$ Engl J Med 2012, 367:2375-2384.

14. Vamos EP, Millett C, Parsons C, Aylin P, Majeed A, Bottle A: Nationwide study on trends in hospital admissions for major cardiovascular events and procedures among people with and without diabetes in England, 2004-2009. Diabetes Care 2012, 35:265-272.

15. Instituto Nacional de Gestión Sanitaria, Ministerio de Sanidad y Consumo: Conjunto Mínimo Básico de Datos, Hospitales del INSALUD. http://www. ingensa.msc.es/estadEstudios/documPublica/pdf/CMBD-2001.pdf. 
16. Charlson ME, Pompei $P$, Ales $K L$, Mackenzie CR: A new method of classifying prognostic comorbidity in longitudinal studies: development and validation. J Chronic Dis 1987, 40:373-383

17. Thomsen RW, Nielsen JS, Ulrichsen SP, Pedersen L, Hansen AM, Nilsson T: The Danish Centre for Strategic Research in Type 2 Diabetes (DD2) study: Collection of baseline data from the first 580 patients. Clin Epidemiol 2012, 4:43-48.

18. Instituto Nacional de Estadística (INE): Population estimates. 2010. http://ine.es/jaxi/menu.do?type=pcaxis\&path=7t20/p259/\&file=inebase

19. Kim HJ, Fay MP, Feuer EJ, Midthune DN: Permutation tests for joinpoint regression with applications to cancer rates. Stat Med 2000, 19:335-351.

20. National Cancer Institute: Joinpoint Regression Program, Version 4.0.4; Statistical Methodology and Applications Branch, Surveillance Research Program. National Cancer Institute. May 2013.

21. Ouhoummane N, Abdous B, Louchini R, Rochette L, Poirier P: Trends in postacute myocardial infarction managmenent and mortality in patients with diabetes. A population-based study from 1995 to 2001. Can J Cardiol 2010, 26:523-531

22. Bottle A, Millet C, Khunti K, Majeed A: Trends in cardiovascular admissions and procedures for people with and without diabetes in England, 1996-2005. Diabetologia 2009, 52:74-80.

23. Rana JS, Venkitachalam L, Selzer F, Mulukutla SR, Marroquin OC, Laskey WK, Holper EM, Srinivas VS, Kip KE, Kelsey SF, Nesto RW, NHLBl-sponsored PTCA and Dynamic Registries Investigators: Evolution of percutaneous coronary intervention in patients with diabetes. A report from the National Heart, Lung, and Blood Institute-sponsored PTCA (1985-1986) and Dynamic (1997-2006) Registries. Diabetes Care 2010, 33:1976-1982.

24. Verma S, Farkouh ME, Yanagawa B, Fitchett DH, Ahsan MR, Ruel M, Sud S, Gupta M, Singh S, Gupta N, Cheema AN, Leiter LA, Fedak PWM, Teoh H, Latte DA, Fuster V, Friedrich JO: Comparison of coronary artery bypass surgery and percutaneous coronary intervention in patients with diabetes: a meta-analysis of randomised controlled trials. Lancet Diabetes Endocrinol 2013, 1:317-328.

25. Contini GA, Nicolini F, Fortuna D, Pacini D, Gabbieri D, Vignali L, Valgimigli M, Manari A, Zussa C, Guastaroba P, De Palma R, Grilli R, Gherli T: Five-year outcomes of surgical or percutaneous myocardial revascularization in diabetic patients. Int J Cardiol 2013, 168:1028-1033.

26. Mazurek M, Kowalczyk J, Lenarczyk R, Zielinska T, Sedkowska A, Pruszkowska-Skrzep P, Swiatkowski A, Sredniawa B, Kowalski O, Polonski L, Strojek K, Kalarus Z: The prognostic value of different glucose abnormalities in patients with acute myocardial infarction treated invasively. Cardiovasc Diabetol 2012, 11:78.

27. Kuramitsu S, Yokoi H, Domei T, Nomura A, Watanabe H, Yamaji K, Soga Y, Arita T, Kondo K, Shirai S, Ando K, Sakai K, Iwabuchi M, Nosaka H, Nobuyoshi M: Impact of post-challenge hyperglycemia on clinical outcomes in japanese patients with stable angina undergoing percutaneous coronary intervention. Cardiovasc Diabetol 2013, 12:74

28. Kassaian SE, Goodarzynejad H, Boroumand MA, Salarifar M, Masoudkabir F, Mohajeri-Tehrani MR, Pourhoseini H, Sadeghian S, Ramezanpour N, Alidoosti M Hakki E, Saadat S, Nematipour E: Glycosylated hemoglobin (HbA1c) levels and clinical outcomes in diabetic patients following coronary artery stenting. Cardiovasc Diabetol 2012, 11:82

29. Holper EM, Abbott JD, Mulukutla S, Vlachos H, Selzer F, McGuire D, Faxon DP, Laskey W, Srinivas VS, Marroquin OC, Jacobs AK: Temporal changes in the outcomes of patients with diabetes mellitus undergoing percutaneous coronary intervention in the National Heart, Lung, and Blood Institute dynamic registry. Am Heart J 2011, 161:397-403.

30. Hillegass WB, Patel MR, Klein LW, Gurm HS, Brennan JM, Anstrom KJ, Dai D, Eisenstein EL, Peterson ED, Messenger JC, Douglas PS: Long-Term Outcomes of Older Diabetic Patients After Percutaneous Coronary Stenting in the United States. J Am Coll Cardiol 2012, 60:2280-2289.

31. Hassan A, Newman A, Ko DT, Rinfret S, Hirsch G, Ghali WA, Tu JV: Increasing rates of angioplasty versus bypass surgery in Canada, 1994-2005. Am Heart J 2010, 160:958-965.

32. Elbarouni B, Ismaeil N, Yan RT, Fox KA, Connelly KA, Baer C, DeYoung JP, Gallo R, Ramanathan K, Pesant Y, Leiter LA, Goodman SG, Yan AT: Temporal changes in the management and outcome of Canadian diabetic patients hospitalized for non-ST-elevation acute coronary syndromes. Am Heart J 2011, 162:347-355

33. Kang JS, Goodman SG, Yan RT, Lopez-Sendon J, Pesant Y, Graham JJ, Fitchett D, Wong GC, Rose BF, Spencer FA, Yan AT, Canadian GRACE and CANRACE Investigators: Management and Outcomes of Non-ST Elevation Acute Coronary Syndromes in Relation to Previous Use of Antianginal Therapies (from the Canadian Global Registry of Acute Coronary Events [GRACE] and Canadian Registry of Acute Coronary Events [CANRACE]). Am J Cardiol 2013, 112:51-56.

34. García-Armesto S, Abadía-Taira MB, Durán A, Hernández-Quevedo C, Bernal-Delgado E: Spain: Health system review. Health Syst Transit 2010, 12:1-295.

35. Boyle S: United Kingdom (England): Health system review. Health Syst Transit 2011, 13:1-486

36. Maier B, Thimme W, Kallischnigg G, Graf-Bothe C, Rohnisch JU, Hegenbarth C, Theres H, Berlin Myocardial Infarction Registry: Does diabetes mellitus explain the higher hospital mortality of women with acute myocardial infarction? Results from the Berlin Myocardial Infarction Registry. J Investig Med 2006, 54:143-151.

37. Champney KP, Veledar E, Klein M, Samady H, Anderson D, Parashar S, Wenger N, Vaccarino $V$ : Sex-specific effects of diabetes on adverse outcomes after percutaneous coronary intervention: trends over time. Am Heart J 2007, 153:970-978.

38. Blöndal M, Ainla T, Marandi T, Baburin A, Eha J: Sex-specific outcomes of diabetic patients with acute myocardial infarction who have undergone percutaneous coronary intervention: a register linkage study. Cardiovasc Diabetol 2012, 11:96

39. López-de-Andrés A, Martínez-Huedo MA, Carrasco-Garrido P, Hernández-Barrera V, Gil-de-Miguel A, Jimenez-Garcia R: Trends in lower-extremity amputations in people with and without diabetes in Spain, 2001-2008. Diabetes Care 2011 34:1570-1576.

40. López de Andrés A, Jiménez-García R, Hernández-Barrera V, Gil-de-Miguel A, Jiménez-Trujillo Ml, Carrasco-Garrido P: Trends in utilization and outcomes of bariatric surgery in obese people with and without type 2 diabetes in Spain (2001-2010). Diabetes Res Clin Pract 2013, 99:300-306.

41. Ruiz-Ramos M, Escolar-Pujolar A, Mayoral-Sánchez E, Corral-San Laureano F, Fernández-Fernández I: Diabetes mellitus in Spain: death rates, prevalence impact, costs and inequalities. Gac Sanit 2006, 20:15-24.

42. Ferreira-González I, Cascant P, Pons JM, Mitjavila F, Salas T, Permanyer-Miralda G: Predicting in-hospital mortality with coronary bypass surgery using hospital discharge data: comparison with a prospective observational study. Rev Esp Cardiol 2008, 61:843-852.

\section{doi:10.1186/1475-2840-13-3}

Cite this article as: Lopez-de-Andres et al:: National trends in utilization and outcomes of coronary revascularization procedures among people with and without type 2 diabetes in Spain (2001-2011). Cardiovascular Diabetology 2014 13:3.

\section{Submit your next manuscript to BioMed Central and take full advantage of:}

- Convenient online submission

- Thorough peer review

- No space constraints or color figure charges

- Immediate publication on acceptance

- Inclusion in PubMed, CAS, Scopus and Google Scholar

- Research which is freely available for redistribution 